\title{
Religión y relaciones laborales en las entidades públicas y privadas en España
}

\section{Religion and Labor Relations in Public and Private Entities in Spain}

\section{Santiago CAÑMARES ARRIBAS \\ Profesor Titular de Derecho Eclesiástico del Estado \\ Universidad Complutense de Madrid. Facultad de Derecho. Madrid \\ orcid 0000-0003-4081-6752 \\ sca@der.ucm.es}

Resumen: En este trabajo se analiza la protección de la libertad religiosa del trabajador en el ámbito laboral, a través de las excepciones que se reconocen en la normativa vigente a la prohibición de discriminación por razón de religión, que vienen condicionadas por la Directiva Europea 2000/78, de 27 de noviembre. A pesar de su falta de transposición al Derecho español, se aborda también el derecho de las confesiones religiosas y empresas de tendencia a discriminar a sus trabajadores por razón de religión y a someterles a obligaciones de lealtad frente a su doctrina o ideario.

Palabras clave: Igualdad y no discriminación religiosa, Relaciones laborales, Derecho europeo, Confesiones religiosas, Empresas de tendencia.
Abstract: This paper focuses on the protection of religious freedom in the workplace by looking at the exceptions in current legislation governing the prohibition of discrimination on religious grounds, in line with European Directive 2000/78. Although it has not been transposed into Spanish law, this paper also addresses the right of religious denominations and ethos-based organizations to discriminate against workers on religious grounds and to require allegiance to their doctrine or ethos.

Keywords: Religious Equality and Non-Discrimination, Labour Relations, European Law, Religious Denominations, Ethos-Based Organizations. 
SUMARIO: 1. Introducción. 2. Igualdad y no discriminación religiosa de los trabajadores en la Ley. 2.1. Las derogaciones generales de la probibición de discriminar en Derecho Comunitario. 2.1.1. Discriminación para proteger la libertad religiosa de los trabajadores. 2.1.2. Discriminación religiosa y acción positiva para compensar desventajas. 2.2. Excepciones en el derecho español a la probibición de discriminación en la Ley. 3. Igualdad y no discriminación religiosa en las relaciones laborales. 3.1. Excepciones a la probibición de discriminar a favor de los empresarios en general. 3.1.1. Discriminación religiosa directa. 3.1.2. Discriminación indirecta. 3.2. Discriminación religiosa directa de trabajadores por confesiones y empresas de tendencia. 3.2.1. Las previsiones de la Directiva. 3.2.2. Derecho español. 3.3. El sometimiento de los trabajadores de confesiones religiosas y empresas de tendencia a obligaciones acrecentadas de lealtad. 3.3.1. Las previsiones de la Directiva. 3.3.2. Derecho español. 4. Conclusiones.

\section{INTRODUCCIÓN}

on carácter general puede afirmarse que hasta épocas recientes tanto el legislador como los tribunales han prestado escasa atención a las cuestiones relativas a la religión en el ámbito laboral. De hecho, ha sido frecuente considerar que los problemas derivados del ejercicio de la libertad religiosa por el trabajador eran más teóricos que reales -la teoría del falso conflicto- en tanto que él mismo podía reestablecerse autónomamente en su pleno disfrute renunciando a su puesto de trabajo y buscándose otro que le resulte compatible con sus convicciones.

Un buen ejemplo de esta tendencia ${ }^{1}$ lo constituyen algunas decisiones de admisibilidad de la desaparecida Comisión de Derechos $\mathrm{Hu}-$ manos. Entre ellas puede citarse Konttinen v. Finlandia (1996) ${ }^{2}$ donde se inadmite la demanda de un trabajador de una empresa de ferrocarri-

1 Para un estudio detallado de esta tendencia, vid. R. NAVArRo-VALls - J. MarTínezTorrón, Conflictos entre conciencia y ley. Las objeciones de conciencia, Iustel, Madrid 2012, 423-427; S. O. CHABID, Religious Accommodation in the Workplace: Improving the Legal Reasoning of the European Court of Human Rights, en AA. Vv., A test of faith? Religious diversity and accommodation in the European workplace, Ashgate Ltd., 2012, 38-41.

2 Dec. Ad. Konttinen v. Finlandia, de 3 de diciembre de 1996. 
les que, después de convertirse a la Iglesia Adventista del Séptimo Día, fue despedido por ausentarse de su puesto de trabajo los viernes a partir de la puesta de sol, en cumplimiento de sus obligaciones religiosas. El trabajador alegó que el despido vulneraba su derecho de libertad religiosa, que ampara que sus días sagrados sean respetados en la medida en que resulte razonable para el empleador y no perjudique los derechos de terceros. La Comisión, en cambio, sostuvo que no afectaba su derecho de libertad religiosa, ya que el demandante no había sido despedido por razón de sus convicciones sino por no haber cumplido con los horarios de trabajo. Además puso de manifiesto que el trabajador planteaba en la demanda un falso conflicto con la libertad religiosa, ya que en caso de que realmente se hubiera producido, el propio empleado podía haberlo resuelto autónomamente renunciando a su puesto de trabajo $^{3}$.

De la misma manera, la Comisión en Stedman v. Reino Unido ${ }^{4}$ (1997), basándose en Konttinen, declaró inadmisible la demanda de una trabajadora que fue despedida de la agencia de viajes en la que trabajaba por no atenerse - por razones religiosas- al requerimiento de trabajar los domingos. De nuevo, la Comisión, acudiendo a la teoría del falso conflicto, afirmó que la trabajadora podía libremente renunciar a su puesto de trabajo y buscarse otro compatible con sus obligaciones religiosas. Además, entendió que la negativa empresarial a permitir que la empleada terminara su jornada con antelación por motivos religiosos no entrañaba discriminación alguna, ya que a los trabajadores pertenecientes a otras confesiones religiosas se les aplicaba el mismo criterio.

En todo caso, esta doctrina de la Comisión ha sido progresivamente superada, tal y como se puede constatar en la Sentencia Eweida v. Reino Unido (2013) del Tribunal Europeo de Derechos Humanos donde se afirmó que «dada la importancia en una sociedad democráti-

3 La Comisión indica, literalmente, lo siguiente: «having found his working hours to conflict with his religious convictions, the applicant was free to relinquish his post. The Commission regards this as the ultimate guarantee of his right to freedom of religion. In sum, there is no indication that the applicant's dismissal interfered with the exercise of his rights under Article 9 para. 1».

4 Vid. Dec. Ad. Stedman v. United Kingdom, de 9 de abril de 1997. 
ca de la libertad de religión, [...] cuando una persona alega una restricción de su libertad religiosa en el lugar de trabajo, en lugar de declarar que la posibilidad de cambiar de trabajo evitaría cualquier injerencia con su derecho, la mejor aproximación sería sopesar la posibilidad de considerar en el balance total si la restricción era proporcionada o no» ${ }^{5}$.

Este nuevo planteamiento está vinculado a un proceso paulatino de concienciación, detectable desde algunas décadas en las sociedades occidentales, acerca de la importancia de proteger adecuadamente el libre ejercicio de la religión en el ámbito laboral, que se ha plasmado en la aprobación de normas orientadas a tutelar al trabajador frente a situaciones de discriminación religiosa. En el contexto europeo es determinante la Directiva 2000/78, de 27 de noviembre, relativa al establecimiento de un marco general para la igualdad de trato en el empleo y la ocupación $^{6}$, a través de la que se pretende armonizar la legislación de los estados miembros, para proteger a los trabajadores frente a situaciones de discriminación directa e indirecta basadas, entre otros motivos, en la religión o en las convicciones ${ }^{7}$.

En todo caso, como la igualdad y la no discriminación no son derechos absolutos, la propia Directiva contempla excepciones a su contenido, algunas de carácter general, motivadas por la necesidad de proteger intereses públicos relevantes -los derechos fundamentales de los demás, la seguridad pública, el orden público, la salud pública etc.- y otras de carácter particular, que responden a la necesidad de propiciar que los empresarios puedan cumplir sus legítimos objetivos empresariales eligiendo los recursos humanos que resulten más adecuados para el desarrollo de su actividad. Esta necesidad se considera aún más palmaria en el caso de las confesiones religiosas y empresas de tendencia, por lo que se les permite discriminar a sus trabajadores por motivos religiosos de una manera más amplia que al común de los empresarios como medio para garantizar el cumplimiento de sus propios fines.

5 Sentencia Eweida y otros v. Reino Unido, de 15 de enero de 2013, ap. 83, in fine.

6 Directiva 2000/78/CE del Consejo, de 27 de noviembre de 2000, relativa al establecimiento de un marco general para la igualdad de trato en el empleo y la ocupación (DO 2000, L 303, 16).

7 Una visión general sobre esta temática puede verse en S. CogLIEvINA, Diritto antidiscriminatorio e religione nel diritto dell'Unione Europea, Derecho y Religión 11 (2016) 4666. 
A lo largo de este trabajo analizaré cuál es la protección que se dispensa a la religión en el ámbito laboral, atendiendo principalmente a cómo se interpretan y aplican por el Tribunal de Justicia de la Unión Europea las excepciones a la prohibición de discriminar contenidas en la Directiva europea y a cuáles han sido los términos de su transposición en nuestra normativa laboral y de su aplicación por nuestros tribunales.

\section{IGUALDAD Y NO DISCRIMINACIÓN RELIGIOSA DE LOS TRABAJADORES EN LA LEY}

\subsection{Las derogaciones generales de la probibición de discriminar en Derecho Comunitario}

La Directiva 2000/78CE, de 27 de noviembre, que encuentra su fundamento último en el derecho fundamental a la igualdad consagrado en el artículo 20 de la Carta de Derechos Fundamentales de la Unión $^{8}$, establece una serie de excepciones al principio de igualdad admitiendo, por una parte, la aprobación de disposiciones nacionales contrarias a la igualdad de trato cuando sea necesario para proteger algún interés preponderante y, por otra, la adopción de medidas de acción positiva -la llamada "discriminación positiva"- para compensar aquellas desventajas que tradicionalmente hayan podido padecer determinadas personas por razón de sus características personales. En uno y otro caso, se trata de excepciones que responden a lo dispuesto en el artículo 52 de la Carta, donde se admite la limitación proporcional de los derechos en ella reconocidos para la protección de intereses públicos relevantes, en los términos establecidos por el Convenio Europeo de Derechos Humanos?.

8 Tal y como declara la Directiva en su Exposición de Motivos, su fundamento inmediato se encuentra en el artículo 19 del Tratado de Lisboa, (antiguo artículo 13 del Tratado de la CE) donde se autoriza al Consejo de la Unión a adoptar medidas para combatir la discriminación basada en el sexo, raza, origen étnico, religión o creencia, discapacidad, edad u orientación sexual.

9 Vid. Explicaciones del Praesidium de la Comisión Europea sobre el contenido de la Carta de Derechos Fundamentales de la Unión, Diario Oficial de la Unión Europea (DOCE), de 14 de diciembre de 2007. 


\subsubsection{Discriminación para proteger la libertad religiosa de los trabajadores}

La norma comunitaria dispone en su artículo 2.5 que los estados miembros pueden establecer en su derecho interno algunas excepciones a su contenido que sean necesarias en una sociedad democrática para proteger la seguridad pública, la defensa del orden y la prevención de infracciones penales, la protección de la salud y la protección de los derechos y libertades de los ciudadanos.

De esta manera, la protección de la libertad religiosa de los trabajadores podría justificar que se contemplaran normativamente excepciones a la regla de la igualdad y no discriminación. En este sentido, es fácil constatar como la legislación de algunos países europeos -como es nuestro caso- contempla el derecho de los fieles de algunas confesiones a descansar en aquellas fechas consideradas como festividades religiosas. En estos supuestos, nos encontramos, sin duda, ante excepciones al principio de igualdad consagrado en la Directiva que se justifican por la necesidad de proteger la libertad religiosa de los trabajadores. Esto presupone -parece innecesario recordarlo- que, más allá de adscripciones formales a unas u otras confesiones, el descanso religioso debe responder a una verdadera convicción del trabajador que alcanza un nivel de seriedad, obligatoriedad, coherencia e importancia tal ${ }^{10}$, que es capaz de excepcionar el cumplimiento de una regla general.

En este sentido, es oportuno traer a colación la Sentencia Kosteski del Tribunal Europeo de Derecho Humanos (2006) donde se desestimó la demanda de un trabajador -supuestamente cristiano- que alegaba la vulneración de su libertad religiosa a raíz de que le fuera denegado el descanso en fechas que la legislación macedonia reservaba solamente a los musulmanes, por el hecho de no quedar suficientemente acreditado que tuviera obligación de observar esas festividades religiosas. El Tribunal de Estrasburgo dejó claro que cuando el trabajador reclama el disfrute de un privilegio frente a los demás empleados, puede ser requerido a acreditar la seriedad de sus convicciones, incluso cuando la le-

10 Por todas, vid. Sentencia Campbell \& Cosans v. Reino Unido, de 25 de febrero de 1982, ap. 36. 
gislación le reconoce el derecho al descanso por una cuestión de adscripción meramente formal a una confesión religiosa ${ }^{11}$.

En todo caso, al margen de su reconocimiento normativo en casos concretos, el derecho al descanso religioso encuentra cobertura, de una manera abstracta, a través del llamado derecho de acomodo de las creencias religiosas del trabajador que genera en el empleador la obligación de proporcionarle una adaptación de las convicciones religiosas, salvo que le hagan incurrir en un perjuicio excesivo o injusto ${ }^{12}$. Su reconocimiento, en todo caso, también supone un tratamiento diferenciado de los trabajadores por razón de sus creencias religiosas que se justifica por la necesidad de proteger su libre ejercicio de la religión.

A la hora de valorar el impacto que puede presentar el reconocimiento normativo de festividades religiosas sobre la igualdad de los trabajadores no creyentes, es importante hacer referencia a la Sentencia Cresco Investigations ${ }^{13}$ (2019) del Tribunal de Justicia de la Unión Europea, donde se viene a resolver una cuestión prejudicial planteada por un tribunal austriaco en relación con la compatibilidad con la Directiva comunitaria de una disposición nacional -la Ley del Descanso Laboral- que reconocía como festivo el Viernes Santo, con carácter retribuido y no recuperable, para los fieles de algunas Iglesias cristianas ${ }^{14}$, al tiempo que disponía, para el caso de que fueran obligados a trabajar, una compensación económica equivalente a una paga extra de salario ${ }^{15}$.

El Tribunal europeo consideró que la norma austriaca entrañaba una discriminación directa de los trabajadores por razón de religión que no resultaba justificada en el marco del artículo 2.5 de la Directiva, ya que ex-

11 Sentencia Kosteski v. Antigua República Yugoslava de Macedonia, de 13 de abril de 2006, ap. 39.

12 Sobre el derecho a la acomodación de las creencias religiosas en el ámbito laboral me remito a mi trabajo, S. CAÑAMARES ARRIBAS, Igualdad religiosa en las relaciones laborales, Aranzadi, 2018, 57-112.

13 Sentencia del Tribunal de Justicia de la Unión Europea, (Gran Sala) de 22 de enero de 2019. (Asunto C-193/17) Cresco Investigation GmbH v. Markus Achatzi.

14 El artículo 7.3 de la Ley de Descanso Laboral dispone lo siguiente: «Para los miembros de las Iglesias Evangélicas de la confesión de Augsburgo y de la confesión helvética, de la Iglesia Católica Antigua y de la Iglesia Evangélica Metodista, también será festivo el Viernes Santo».

15 Un estudio detallado de este pronunciamiento puede verse en S. CAÑAMARES ARRIBAS, Festividades religiosas e igualdad laboral, Revista La Ley Unión Europea Mayo (2019). 
cedía lo estrictamente necesario en una sociedad democrática para proteger la libertad religiosa de los trabajadores de las confesiones concernidas.

En efecto, las excepciones a la Directiva deben interpretarse en términos restrictivos ${ }^{16}$, por lo que es necesario valorar hasta qué punto la medida discriminatoria es adecuada y necesaria para la protección de la libertad religiosa de los referidos trabajadores ${ }^{17}$. En este caso, es preciso señalar que la discriminación establecida en la Ley austriaca no derivaba del reconocimiento del Viernes Santo como día festivo a los fieles de determinadas Iglesias cristianas sino de su carácter retribuido y no recuperable, así como del reconocimiento del derecho a percibir una compensación en caso de cualquiera de ellos se viera obligado a trabajar en ese día.

Sin embargo, el Tribunal parece sostener que, al margen de cualquier retribución económica, el reconocimiento mismo del descanso que se contiene en la norma austriaca es discriminatorio en tanto genera un impacto desproporcionado en los demás trabajadores al no quedar asociado con la celebración de determinadas actividades litúrgicas. En este punto es importante destacar que hay confesiones religiosas que imponen a sus fieles el descanso en una determinada fecha sin acompañarlo necesariamente de la obligación de conmemorar la festividad a través de la participación en ceremonias religiosas. De esta manera, el reconocimiento del derecho al descanso por la mera pertenencia a una determinada confesión religiosa -sin supeditarlo al cumplimiento de ulteriores obligaciones religiosas- no puede entenderse como una quiebra en la lógica del sistema, en tanto la excepción a la regla de la igualdad de los trabajadores sigue teniendo una justificación objetiva: la

16 Como ha puesto de manifiesto el Tribunal de Justicia en varias decisiones, este artículo, en tanto constituye una excepción a la prohibición de discriminación, debe ser interpretado en términos restrictivos. Vid. Sentencia C-341/08 Petersen v Berufungsausschuss für Zahnärzte für den Bezirk Westfalen-Lippe, ap. 60; C-447/09, Prigge and Others v. Deutsche Lufthansa $A G$.

17 Vid. Aps. 54-55. Sin embargo, no comparto la interpretación restrictiva que hace el Abogado General de la referencia contenida en el artículo 2.5 a la protección de los derechos de los ciudadanos. Si se pone en conexión esta redacción con el artículo 52 de la Carta de Derechos Fundamentales de la Unión y con los principales textos internacionales de protección de derechos humanos, se llega a la conclusión de que la protección de los derechos de cualquier individuo -y no exclusivamente de los de la sociedad en su conjunto- es susceptible de limitar el ejercicio de otros derechos fundamentales, entre ellos, el de la igualdad religiosa. Vid. Opinión del Abogado General Bobek, aps. 93 y ss. 
obligación del descanso religioso. En consecuencia, si la obligación religiosa no exigiera el descanso sino la participación en una ceremonia en concreto, la libertad religiosa del trabajador quedaría suficientemente tutelada reconociéndole el permiso para asistir a dicha celebración por el tiempo que resultara estrictamente necesario.

Dejando al margen esta precisión, parece claro que el reconocimiento de los derechos retributivos que la ley austriaca asocia al descanso religioso sí que puede resultar contrario al principio de proporcionalidad, ya que este exige que el tratamiento diferenciado tenga sobre los demás trabajadores, en términos de igualdad y no discriminación, el mínimo impacto necesario para salvaguardar la libertad religiosa de los creyentes. A este respecto, resulta suficiente con reconocer la ausencia del empleado en Viernes Santo sin mayores aditamentos, esto es, al margen de cualquier retribución salarial o compensación económica, en caso de acudir al trabajo ${ }^{18}$.

Podría argumentarse que tales prestaciones económicas constituyen un recurso orientado a una mayor protección de la libertad religiosa del trabajador en tanto le permite el libre ejercicio de su religión sin merma en su nivel de vida. Sin embargo, este planteamiento, que excede de lo estrictamente necesario para la garantía de este derecho, podría ser admisible si no presentara un impacto excesivo -por desproporcionado- en la igualdad religiosa de los demás trabajadores.

En todo caso, el Tribunal de Justicia constata que en derecho austriaco también se reconoce -al margen de una disposición normativa explícita- el derecho de los trabajadores a descansar en el día previsto por sus propias convicciones "a través del deber de asistencia y protección” que tienen los empleadores frente a sus empleados. Es decir, a través de esta previsión se hace posible el descanso religioso de los trabajadores de cualquier confesión -al margen de su reconocimiento normativo ad casum - y sin vincularlo con el derecho a recibir remuneración alguna o compensación en caso de que no se autorice por el empleador. De ahí concluye el Tribunal que las medidas discriminatorias contenidas en la Ley de Descanso Laboral exceden lo necesario en una socie-

18 Como apunta el Abogado General en sus conclusiones, es difícil considerar que la obtención de una paga extra en caso de inobservancia de la festividad religiosa pueda contribuir al libre ejercicio de la religión. Vid. ap. 69. 
dad democrática para proteger la libertad religiosa de los trabajadores de las referidas Iglesias, con lo que no pueden quedar justificadas en el marco del artículo 2.5 de la Directiva ${ }^{19}$.

Desde luego, aplicando una perspectiva comparada, la regulación contenida en la legislación austriaca bien puede calificarse de excepcional. En efecto, la legislación de otros países europeos excluye expresamente el carácter retribuido del descanso religioso y, desde luego, no lo asocia con compensaciones económicas en caso de que no sea respetado. En nuestro Derecho, tanto el Acuerdo de asuntos jurídicos de 1979 como los acuerdos de 1992 con las confesiones minoritarias no contienen ninguna referencia a posibles compensaciones económicas por el descanso en festividades religiosas. En Italia, de una forma más explícita, la Intesa firmada entre la República Italiana y la Unión de Comunidades Israelitas de Italia, reconoce, en sus artículos 2 y 3 , a los trabajadores judíos del sector público y privado el derecho a descansar el sábado y en las festividades allí identificadas, con obligación de recuperar las horas dejadas de trabajar y sin derecho a compensación económica alguna ${ }^{20}$.

\subsubsection{Discriminación religiosa y acción positiva para compensar desventajas}

La Directiva europea recoge también, como excepción a su contenido, la llamada discriminación positiva en su artículo 7 «con el fin de garantizar la plena igualdad en la vida profesional». Esto significa que el principio comunitario de igualdad de trato no impide que un Estado miembro mantenga o adopte medidas específicas destinadas a prevenir o compensar las desventajas ocasionadas por cualquiera de las caracte-

19 Vid. Sentencia Cresco Investigations, aps. 60-61.

20 Vid. Intesa tra la Repubblica italiana e l'Unione delle Comunità Israelitiche Italiane. El texto de este Acuerdo está disponible en: http://host.uniroma3.it/progetti/cedir/ cedir/Ist-rel/It_int_Isr.pdf (última visita 8 de febrero de 2019). El citado artículo 3 tiene, en la parte que nos interesa la siguiente redacción: «Gli ebrei dipendenti dallo Stato,da enti pubblici o da privati o che esercitano attività autonoma o commerciale i militari e coloro che siano assegnati al servizio civile sostitutivo, hanno diritto di fruire, su loro richiesta, del riposo sabbatico come riposo settimanale. Tale diritto è esercitato nel quadro della flessibilità dell'organizzazione del lavoro. In ogni altro caso le ore lavorative non prestate il sabato sono recuperate la domenica o in altri giorni lavorativi senza diritto ad alcun compenso straordinario». 
rísticas a que se refiere esta norma europea. Se trata, en definitiva, de una excepción formal a la prohibición de discriminación, que se orienta hacia la consecución de una igualdad material ${ }^{21}$. En todo caso, como cualquier excepción al contenido de la Directiva, este tipo de medidas deben interpretarse en sentido restrictivo y ser proporcionadas a los fines perseguidos, de modo que no sobrepasen lo estrictamente necesario para su consecución.

Como manifestación de esta discriminación positiva en materia religiosa, la propia Directiva, en su artículo 15, contempla la posibilidad de que la legislación de Irlanda del Norte permita discriminar, por motivos religiosos, a quienes pretenden acceder a los cuerpos de policía o trabajar como maestros de escuela, para compensar la infra-representación de algunas comunidades religiosas en estos oficios.

Sin embargo, más allá de este supuesto concreto, que viene a remediar desequilibrios entre dos grupos religiosos mayoritarios que han estado en la base de décadas de confrontación armada, no parece que la discriminación positiva pueda resultar aplicable en materia religiosa, al menos en aquellos estados que han adoptado la laicidad o la neutralidad religiosa como principio constitucional, pues -como hemos dicho- este tipo de acciones podrían entenderse como un respaldo indebido por parte de los poderes públicos a una o varias opciones religiosas concretas ${ }^{22}$.

El Tribunal de la Unión Europea también analizó en Cresco Investigations en qué medida el reconocimiento del Viernes Santo como festivo de carácter retribuido y no recuperable podía considerarse como una

21 E. Relaño, Towards Substantive Equality for Religious Believers in the Workplace? Two Supranational European Courts, Two Different Approaches, Oxford Journal of Law and Religion 5, 2 (2016) 255 y ss.

22 A. López-Sidro LóPez - R. PALOMINO LozANo, «¿ Cabe la discriminación positiva en relación con el factor religioso?», Revista General de Derecho Canónico y de Derecho Eclesiástico del Estado 25 (2011) 18 y ss. Otros autores, en cambio, ven posible este tipo de discriminación positiva, quizá porque no reparen en las apuntadas repercusiones sobre la laicidad y neutralidad ya que, consideran admisible que la legislación estatal permita que un empresario discrimine positivamente a los posibles trabajadores que pertenezcan a confesiones determinadas para proporcionarles una mayor presencia en la empresa bajo el principio de la diversidad cultural y religiosa. Vid. H. HoWARD, Study on the implementation of Directive 2000/78/EC with regard to the principle of non-discrimination on the basis of religion or belief, cit., EPRS (2016) 55. Texto accesible en: http://www.europarl.europa.eu/RegData/etudes/STUD/2016/536345/EPRS _STU\%282016\%29536345_EN.pdf (última visita 11 de junio de 2018). 
medida específica destinada a compensar una "desventaja" de los fieles de las referidas confesiones religiosas. A su juicio, tales medidas -descanso retribuido- exceden el concepto de "acción positiva" de la Directiva por dos razones fundamentales: de un lado, porque no resultan proporcionadas a los fines perseguidos, ya que van más allá de lo necesario -el reconocimiento del descanso en Viernes Santo- para conjurar la situación de desventaja; $y$, de otro, porque no respetan el principio de igualdad, dado que al tener un carácter selectivo -aplicable solo a las referidas Iglesias cristianas- generan una discriminación de segundo nivel frente a aquellos trabajadores que, a pesar de encontrarse en una situación de desventaja similar por no haber podido disfrutar del descanso en días importantes para su religión, no podrían disfrutar de la misma medida específica de compensación, esto es, la retribución del festivo religioso ${ }^{23}$.

Por lo demás, parecen atinadas las Conclusiones del Abogado General Bobek en este asunto, donde calificaba de "prácticamente milagroso" que una disposición como la Ley austriaca de Descanso Laboral, que entró en vigor a mediados del siglo XX, pudiera concebirse como una "acción positiva" para compensar las desventajas que históricamente hubiera padecido determinada categoría de personas por razón de sus creencias religiosas ${ }^{24}$. En todo caso, consideró que la compensación planteada en la legislación para los miembros de las referidas confesiones no se ajustaba al concepto de "acción positiva" por una doble razón: de un lado, por su carácter selectivo, en tanto no compensa a cualquier grupo que en el pasado no hubiera podido descansar en un día de celebración religiosa importante. Y, de otro, porque no respeta el principio de proporcionalidad por exceder lo estrictamente necesario para compensar la situación de desventaja.

\subsection{Excepciones en el derecho español a la probibición de discriminación en la Ley}

$\mathrm{Al}$ proyectar la igualdad, como principio, sobre la libertad religiosa, nuestro Tribunal Constitucional ha afirmado que no es posible esta-

23 Vid. Conclusiones del Abogado General Michal Bobek, de 25 de julio de 2018, Asunto C-193/17 Cresco Investigation GmbH v. contra Markus Achatzi, ap. 110.

24 Vid. Conclusiones del Abogado General Michal Bobek, ap. 108. 
blecer ningún tipo de discriminación o de trato jurídico diverso de los ciudadanos en función de sus ideologías o sus creencias y que debe existir un igual disfrute de la libertad religiosa por todos los ciudadanos, lo que implica que las actitudes religiosas de los sujetos de derecho no pueden justificar diferencias de trato jurídico ${ }^{25}$.

Sin embargo, la aplicación de este principio no impide a los poderes públicos contemplar la necesidad o la conveniencia de diferenciar situaciones distintas y de darles un tratamiento diverso ${ }^{26}$. La apreciación de en qué medida la Ley ha de contemplar situaciones distintas que no deben ser tratadas igualmente, queda, con carácter general, confiada al legislador. Pero tal valoración tiene unos límites, ya que no puede ser contraria a los derechos reconocidos en la Constitución o a cualquier precepto o principio de la misma.

Centrándonos en el ámbito de las relaciones laborales, nuestra legislación contempla algunas excepciones a las reglas generales de descanso laboral orientadas a proteger el derecho de libertad religiosa de los trabajadores. Cabe aludir, en este sentido, que frente a lo dispuesto en el artículo 37 del Estatuto de los Trabajadores -que establece el descanso semanal en domingo y señala una serie de fiestas nacionales con carácter retribuido y no recuperable- los acuerdos con las confesiones religiosas minoritarias (1992) identifican una serie de celebraciones religiosas en las que sus fieles tienen derecho a descansar siempre que haya acuerdo con el empleador ${ }^{27}$.

El Tribunal Constitucional en su Sentencia 19/1985, de 13 de febrero, analizó en qué medida el reconocimiento del domingo como día de descanso semanal entrañaba una discriminación de aquellos trabaja-

25 Vid. Sentencia del Tribunal Constitucional 24/1982, de 13 de mayo. Fundamento jurídico primero.

26 Vid. Sentencia del Tribunal Constitucional 34/1981, de 10 de noviembre. Fundamento jurídico tercero.

27 Vid. art. 12 de la Ley 25/1992, de 26 de noviembre, por la que se aprueba el Acuerdo de cooperación con la Federación de Comunidades Judías de España; art. 12 de la Ley 26/1992, de 26 de noviembre, por la que se aprueba el Acuerdo de cooperación con la Comisión Islámica de España. La Ley 24/1992, de 26 de noviembre por la que se aprueba el Acuerdo de cooperación con la Federación de Entidades Religiosas Evangélicas de España (FEREDE), contempla también el descanso en sábado en sustitución del domingo siempre que medie acuerdo entre las partes. 
dores que por motivos religiosos estaban obligados a descansar en un día distinto ${ }^{28}$.

Se trataba de analizar -en palabras del propio Tribunal- si «el descanso semanal, instituido, por lo general, en un periodo que comprende el domingo, tiene o no una conceptuación religiosa que pueda hacer cuestionable que la Ley establezca un régimen favorable para unos creyentes y desfavorables para otros, partiendo de que la libertad religiosa, comporta, en aplicación del principio de igualdad, el tratamiento paritario de las distintas confesiones ${ }^{29}$.

El Tribunal concluyó que no podía estimarse dicha disposición como discriminatoria porque el descanso semanal en domingo constituye -sin obviar sus orígenes religiosos- una tradición laboral y secular «porque este día de la semana es el consagrado por la tradición» ${ }^{30}$. Por lo demás, afirma que, en nuestro Derecho, el descanso semanal tiene un carácter dispositivo, por lo que cabe su fijación en cualquier otro día de la semana siempre que medie acuerdo entre las partes. En todo caso, el establecimiento del domingo con carácter preferente responde a una tradición histórica común a los pueblos de civilización cristiana que facilita mejor el cumplimiento de los objetivos del descanso.

Por lo tanto, cualquier trabajador, al margen de una eventual referencia explícita en la Ley, tiene derecho al descanso religioso en aquellas festividades consideradas como sagradas en su respectiva confesión. Para entender adecuadamente el sentido de esta afirmación, debe tenerse en cuenta la posición del Tribunal Constitucional en su Sentencia 204/1997, de 25 de noviembre, donde afirmó que la relación laboral crea un complejo entramado de derechos y obligaciones entre el empresario y el trabajador que condiciona el ejercicio de los derechos fundamentales de este último. Resulta necesario, por tanto, conseguir un equilibrio entre las obligaciones dimanantes del contrato para el trabajador y el ámbito de su libertad constitucional, partiendo del reconocimiento de una posi-

28 Debe tenerse en cuenta que el Acuerdo de Asuntos Jurídicos con la Santa Sede (1979) dispone en su artículo III que «[E]l Estado reconoce como días festivos todos los domingos. De común acuerdo se determinará qué otras festividades religiosas son reconocidas como días festivos».

30 Vid. Fundamento jurídico cuarto. 
ción preeminente a los derechos fundamentales frente al ejercicio de la libertad de empresa, lo que se traduce en que la modulación derivada del contrato de trabajo solo se producirá en la medida estrictamente imprescindible para el logro del legítimo interés empresarial.

La apuntada prevalencia no es sino una consecuencia directa de la dinámica de los derechos fundamentales que exige que su ejercicio sea acomodado en el ámbito laboral cuando no ocasione un perjuicio desproporcionado al empresario. De esta manera, aunque el Tribunal Constitucional, en la citada Sentencia 19/1985, afirmara con acierto que la fijación del descanso laboral tiene carácter dispositivo, dependiendo a la postre de un acuerdo entre trabajador y empresario, su correcta comprensión exige considerar que este último tiene la obligación de acomodar las creencias del trabajador en su organización empresarial, salvo que le acarree un perjuicio excesivo o injusto. En consecuencia, no resulta acertada su posición cuando afirma, en esta Sentencia, que el despido de una trabajadora Adventista del Séptimo Día por no acudir a su puesto de trabajo el sábado -día de descanso impuesto por sus creencias religiosas- resultaba procedente, ya que el cambio en las convicciones religiosas de la empleada no podía entrañar la modificación del contrato de trabajo, firmado con anterioridad a su adhesión adventista, en aquellos aspectos que entraran en conflicto con sus nuevas creencias.

Cumple recordar cómo la trabajadora planteó, antes de que fuera despedida, la posibilidad de cambiar de turno, de ausentarse sin salario o con compensación por otras horas. En este caso, el Tribunal en vez de limitarse a subrayar la inexistencia de un acuerdo entre las dos partes, debería haber exigido al empleador que acreditara el perjuicio excesivo o injusto que le acarrearía acomodar a la trabajadora en los términos solicitados o, en su caso, en otros que fueran aún menos gravosos para él.

\section{IGUALDAD Y NO DISCRIMINACIÓN RELIGIOSA \\ EN LAS RELACIONES LABORALES}

Nos corresponde ahora analizar en qué casos la normativa vigente permite que los empresarios discriminen directa e indirecta a sus trabajadores por razón de religión o convicciones. En aras de una mayor claridad, distinguiré, en primer lugar, las excepciones establecidas en la 
Directiva comunitaria a favor del común de los empresarios de aquellas otras -más amplias- reconocidas a las confesiones religiosas y las empresas de tendencia para, a continuación, valorar su transposición al Derecho español y su aplicación por nuestros tribunales.

\subsection{Excepciones a la probibición de discriminar a favor de los empresarios en general}

\subsubsection{Discriminación religiosa directa}

a) Las previsiones de la Directiva 2000/78

Como es sabido, la discriminación religiosa directa se produce cuando una persona es tratada de forma menos favorable que otra en atención a sus propias convicciones. Tal situación se produciría, por ejemplo, cuando se dejara de contratar o se despidiera a una persona por el hecho de profesar o de convertirse a una determinada religión o por realizar cualquier práctica asociada a sus creencias.

Sin embargo, el art. 4 de la Directiva permite que cualquier empresario discrimine a sus trabajadores por razón de religión o creencia cuando tal característica pueda ser considerada un requisito profesional "esencial y determinante" del puesto de trabajo atendiendo a la naturaleza de la actividad profesional de que se trate o al contexto en que se lleve a cabo, siempre y cuando el objetivo sea legítimo y el requisito proporcionado.

El Tribunal de Justicia de la Unión Europea se ha pronunciado acerca del alcance de esta excepción frente a la discriminación religiosa directa en la sentencia Bougnaoui (2017), donde se resuelve una cuestión prejudicial planteada por la Cour de Cassation francesa en el marco de un proceso de despido de una trabajadora que se negó a desprenderse del velo islámico, a pesar de que la empresa-cliente donde prestaba servicios había manifestado a su compañía su deseo de que no le enviaran más trabajadoras con esta prenda, ya que había causado molestias en alguno de sus empleados ${ }^{31}$.

El Tribunal de Justicia recuerda, ante todo, que solo en muy contadas circunstancias una característica vinculada a la religión puede

31 Sentencia Bougnaoui v. Micropole, SA, de 14 de marzo de 2017, Asunto C-188/15. 
constituir un requisito profesional "esencial y determinante", ya que debe tratarse de un requisito objetivamente dictado por la naturaleza de la actividad profesional de que se trate o por el contexto en que se lleve a cabo. Por tanto, no puede estar basado en consideraciones subjetivas como, en este caso, la voluntad del empresario de tener en cuenta los deseos particulares del cliente. En consecuencia, concluyó que el despido de la trabajadora, por su negativa a desprenderse del velo islámico, constituyó un supuesto de discriminación laboral directa prohibida por la Directiva, ya que la utilización del pañuelo no afectaba al eficaz desempeño de sus tareas por parte de la trabajadora.

Es interesante señalar que la Abogada General Sharpston, que elevó sus conclusiones al Tribunal en este asunto, matizó que la exigencia de que el requisito sea "determinante" quiere decir que «la excepción debe limitarse a cuestiones que sean estrictamente necesarias para desempeñar la actividad profesional en cuestión». De esta forma, el «interés comercial de la empresa» no podía considerarse un objetivo legítimo para justificar la discriminación religiosa directa, teniendo en cuenta que, según el Tribunal de Justicia, las excepciones a la discriminación directa no pueden estar basadas en el perjuicio económico causado al empresario ${ }^{32}$.

\section{b) Discriminación religiosa directa en Derecho español}

Dejando al margen la dificultad de diferenciar, en ocasiones, situaciones de discriminación directa e indirecta, se puede afirmar que, en nuestro Derecho, la discriminación religiosa directa fue apreciada por la Sentencia del Juzgado de lo Social de Palma de Mallorca, de 6 de febrero de 2017, donde se resuelve -de una manera algo confusa- la demanda de una trabajadora del aeropuerto de Palma de Mallorca que fue despedida por su negativa a cumplir con la uniformidad de la compañía, desprendiéndose del velo islámico.

La demandante -que fue sancionada repetidamente con suspensiones de empleo y sueldo- alegó que estaba siendo discriminada por mo-

32 Sobre las observaciones de la Abogada General en relación con este caso puede verse, R. PAlomino, Igualdad y no discriminación religiosa en el Derecho de la Unión Europea. A propósito de las conclusiones en los casos Achbita y Bougnaoui, Revista latinoamericana de Derecho y Religión 2 (2016). 
tivos religiosos «pues otros trabajadores podían exhibir cruces y vírgenes colgadas y visibles, sin ser sancionados, al margen de que otros no hacían un uso riguroso del uniforme portando bolsos y zapatos no reglamentarios o mostrando un aspecto descuidado, con piercings o con tatuajes» ${ }^{33}$.

El Tribunal entendió que la trabajadora había sido objeto de discriminación religiosa ya que la empresa no puso de manifiesto ningún argumento jurídicamente atendible para justificar la prohibición del velo islámico. Simplemente indicó que sus empleados en el departamento de atención al pasajero debían cumplir las normas de uniformidad que no permiten hacer uso de prendas o elementos distintos de los que ella misma proporciona, en defensa de una buena imagen corporativa.

En definitiva, se puede afirmar que el Juzgado consideró, desde la perspectiva del artículo 4.1 de la Directiva europea ${ }^{34}$, que la discriminación directa no podía quedar justificada, ya que la empresa no alegó perjuicio alguno derivado de la utilización del velo islámico por la trabajadora. Se trataba, por tanto, de una cuestión meramente estética, que tenía relevancia en cuanto a la expresión de la imagen de la compañía, pero que no respondía a una política empresarial de neutralidad religiosa. Por lo demás se hace referencia a la existencia de un supuesto "manual de imagen personal y uniformidad" que no prohibiría el uso de símbolos religiosos. Y en fin, parece que otros empleados podían hacer uso de símbolos religiosos y de otra naturaleza sin enfrentarse a sanciones laborales.

33 Vid. Fundamento jurídico tercero.

34 Recuérdese que, conforme a reiterada jurisprudencia del Tribunal de Justicia, las directivas no tienen efecto directo horizontal, de modo que no pueden ser directamente aplicadas en los litigios entre particulares. Vid., por todas, Sentencia, Faccini Dori de 14 de julio de 1994 (C-91/92), ap. 20; Sentencia Bernard Pfeiffer y otros, de 5 octubre de 2004 (C-397/01), en cuyo apartado 108 se afirma: "A este respecto, el Tribunal de Justicia ha declarado, de modo reiterado, que una directiva no puede, por sí sola, crear obligaciones a cargo de un particular y que una disposición de una directiva no puede, por consiguiente, ser invocada, en su calidad de tal, contra dicha persona (véanse, en particular, las sentencias de 26 de febrero de 1986, Marshall, 152/84, Rec., 723, apartado 48”. En consecuencia, en su apartado 109 se aclara que «incluso una disposición clara, precisa e incondicional de una directiva que tiene por objeto conferir derechos o imponer obligaciones a los particulares no puede aplicarse como tal en el marco de un litigio exclusivamente entre particulares». 
En todo caso, al hilo de este pronunciamiento conviene precisar que, conforme a la jurisprudencia del Tribunal de Justicia, la neutralidad empresarial nunca puede constituir un objetivo legítimo para justificar la discriminación religiosa directa de los trabajadores, tal y como recordó la Abogada General Sharpston en su opinión elevada al Tribunal en Bougnaoui ${ }^{35}$, al contrario de lo que ocurre en los casos de discriminación indirecta.

\subsubsection{Discriminación indirecta}

\section{a) Las previsiones de la Directiva 2000/78}

La discriminación indirecta tiene lugar cuando un grupo de personas resultan perjudicadas en relación con otras que se encuentran en su misma situación por razón de una disposición, criterio o práctica empresarial que es intencionadamente neutral pero que, de hecho, les ocasiona una desventaja particular en atención a sus características personales. Esta situación se produciría - por ejemplo- cuando un empresario decidiera, en aras de un interés comercial legítimo, ampliar el horario de trabajo a los sábados, afectando a aquellos trabajadores que tuvieran que descansar por prescripción religiosa durante ese día de la semana.

La Directiva europea contempla también excepciones a la prohibición de discriminación indirecta, admitiendo aquellas disposiciones laborales que, aunque tengan un efecto adverso para determinada categoría de trabajadores, estén objetivamente justificadas por la necesidad de alcanzar una finalidad empresarial legítima y cuando los medios para su consecución sean adecuados y necesarios.

El Tribunal de Justicia vino a pronunciarse sobre el alcance de esta excepción en la Sentencia Achbita ${ }^{36}$ (2017) donde se resuelve una cuestión prejudicial planteada por la Corte de Casación belga en el marco

35 La Abogada General se refiere a unas decisiones del Tribunal de Justicia relativas a una discriminación directa por razón de sexo donde afirmaba que la negativa a la contratación de trabajadoras por razón de embarazo no podía quedar justificada por motivos económicos derivados de que la mujer no pueda ocupar su puesto de trabajo durante su periodo de baja por maternidad o no pueda acudir al trabajo durante el periodo de embarazo. Vid. Conclusiones de la Abogada General Sharpston, ap. 100.

36 Sentencia Achbita v. G4S Secure Solutions, de 14 de marzo de 2017. Asunto C-157/15. 
de un proceso laboral en el que una recepcionista musulmana fue despedida por desobedecer la prohibición empresarial de llevar signos visibles de sus convicciones políticas, filosóficas o religiosas y de observar cualquier rito relacionado con dichas convicciones.

El Tribunal descarta que la trabajadora musulmana haya sido objeto de discriminación directa, ya que su despido trae causa de la inobservancia de una normativa interna que se aplica por igual a todos los trabajadores imponiéndoles, al margen de su afiliación política, religiosa, etc., la prohibición de utilización de cualquier símbolo en base a una política de neutralidad empresarial ${ }^{37}$. Sin embargo, al mismo tiempo, advierte al tribunal remitente que debe analizar en qué medida la citada prohibición pudo entrañar una situación de discriminación religiosa indirecta para la trabajadora.

El Tribunal, al aclarar qué finalidades empresariales pueden considerarse legítimas para justificar la discriminación indirecta de los trabajadores, se refiere a la política empresarial de neutralidad religiosa, desde el momento en que la voluntad del empresario de ofrecer una imagen neutra a sus clientes está vinculada con la libertad de empresa.

En este punto es interesante referirse a las Conclusiones presentadas por la Abogada General Kokott en este caso, donde afirma que entre las finalidades legítimas que pueden justificar una discriminación indirecta se encuentran aquellas que sirven para justificar una discriminación directa (que es más grave), es decir, aquellos requisitos profesionales esenciales y determinantes a la luz de la naturaleza de la actividad o del contexto en que se presta ${ }^{38}$. La Abogada General concluye que la prohibición del velo constituía un requisito profesional esencial y determinante, en atención no tanto a la naturaleza de la actividad profesional (se reconoce que el trabajo de recepcionista puede hacerse igual de bien con velo que sin él) sino por el contexto en que se lleva a cabo,

37 Un análisis crìtico de esta decision puede verse en J. GILEs, Neutrality in the Business Sphere - An Encroachment on Rights Protection and State Sovereignty?, Oxford Journal of Law and Religion 7, Issue 2 (2018) 343-346; A. PIN, Is there a place for Islam in the West? Adjudicating the Muslim headscarf in Europe and the United States, Notre Dame Law Review 35 (2017) 35-43.

38

Vid. ap. 60, donde se sostiene que si un requisito profesional esencial y determinante puede justificar una discriminación directa, con mayor razón podrá legitimar una discriminación indirecta. 
ya que resulta especialmente oportuna una política de neutralidad por la diversidad de los clientes y por la especial naturaleza de las actividades desarrolladas por la trabajadora, que se caracterizan por un contacto permanente cara a cara con terceras personas y que determinan la propia imagen de la compañía.

En lo que se refiere al requisito de que los medios empleados sean adecuados y necesarios, la Sentencia Achbita considera que serán adecuados cuando se apliquen de manera congruente y sistemática a todos los trabajadores que están en contacto con sus clientes. En relación con su necesidad, se debe comprobar si la medida se limita a lo estrictamente necesario, esto es, afecta únicamente a los trabajadores que están en contacto directo con los clientes. En este sentido, apuntó que se debería tomar en consideración si existía la posibilidad de ofrecer a la trabajadora Achbita un puesto de trabajo que no conllevara un contacto visual con los clientes en lugar de proceder a su despido.

\section{b) La discriminación religiosa indirecta en Derecho español}

En lo que se refiere al tratamiento de la discriminación religiosa indirecta por nuestros tribunales, cabe hacer referencia a la Sentencia del Tribunal Superior de Justicia de la Rioja, de 22 de junio de 2017, donde se resuelve el recurso de suplicación interpuesto por una trabajadora musulmana que fue despedida de una empresa agrícola por su negativa a quitarse el velo islámico o, al menos, a cubrirlo por debajo de la bata y gorro que se proporcionaba a todos los empleados por razones de higiene ${ }^{39}$.

Más en concreto, la normativa interna de la empresa, dedicada a la recolección y comercialización del champiñón, establecía que los trabajadores debían emplear una bata que cubriera enteramente su ropa de calle y un gorro para evitar cualquier tipo de contaminación alimentaria. La prohibición venía determinada por la certificación del sistema de calidad. De hecho, un auditor de la empresa certificadora les advirtió

39 Esta sentencia fue recurrida ante el Tribunal Supremo en unificación de doctrina, quien inadmitió el recurso, a través de su Auto de 20 de marzo de 2018, por falta de contradicción entre la recurrida y la pronunciada por el Tribunal Superior de Justicia de Baleares de 9 de septiembre de 2002. 
verbalmente de que podían perder la certificación por el hecho de que la ropa de algunos trabajadores sobresalía por fuera de la bata.

El Tribunal Superior de Justicia, al amparo de la Directiva europea, llegó a la conclusión de que la prohibición del velo islámico no constituía un supuesto de discriminación directa en tanto la prohibición se aplicaba a todos los trabajadores de manera general e indiferenciada, esto es, al margen de sus creencias religiosas. De hecho, la norma no prohibía exclusivamente el hiyab, sino cualquier tipo de prenda que sobresaliera de la bata de trabajo, estando permitido llevar el velo islámico siempre y cuando se recogiera adecuadamente bajo el gorro para que no quedara al descubierto.

La sentencia reconoce que la normativa interna de la empresa presentaba un efecto adverso sobre las trabajadoras musulmanas, entrañando un supuesto de discriminación indirecta. Sin embargo, se trataba de una discriminación admisible ya que, atendiendo a la naturaleza de la actividad, la prohibición perseguía un objetivo legítimo -reducir el riesgo de contaminación alimentaria- y resultaba proporcionada.

\subsection{Discriminación religiosa directa de trabajadores por confesiones $y$ empresas de tendencia}

\subsubsection{Las previsiones de la Directiva}

Una vez analizadas las excepciones a las prohibiciones de discriminar que se reconocen a los empresarios en general, nos corresponde analizar el alcance de estas excepciones cuando el empleador es una confesión religiosa o una empresa de tendencia.

En efecto, la Directiva 2000/78, en su art. 4.2 permite que las confesiones religiosas y las empresas de tendencia puedan discriminar por razón de religión a sus trabajadores de una manera más amplia que si fueran empleadores convencionales cuando la religión, por la naturaleza de las actividades o el contexto en el que se desarrollen, constituya un requisito profesional esencial, legítimo y justificado respecto de la ética de la organización.

Hay, por tanto, tres importantes diferencias en relación con la excepción contemplada en el apartado anterior. En primer lugar, solo se aplica cuando la diferencia de trato se basa en la religión del trabajador. En segundo lugar, el empleador tiene que ser una confesión religiosa o una empresa de tendencia. Y, en tercer lugar, no se requiere que la re- 
ligión o las convicciones constituyan un requisito profesional determinante del puesto de trabajo, siendo suficiente que sea "esencial y justificado", lo que extiende la posibilidad de discriminar por estas razones a trabajadores que no vayan a desempeñar actividades de naturaleza estrictamente religiosa o ideológica, esto es, en los que la característica en cuestión no es determinante para el puesto de trabajo.

\section{a) Ámbito subjetivo}

Una de las cuestiones más complejas que se plantean con esta excepción es qué debe entenderse por «organizaciones públicas o privadas cuya ética se base en la religión o en las convicciones» (empresa de tendencia $)^{40}$. La Directiva guarda silencio al respecto. No obstante, se trata de un concepto que debe ser interpretado restrictivamente porque, de lo contrario, se estaría permitiendo que algunas entidades pudieran discriminar ampliamente a sus trabajadores por motivos religiosos sin justificación alguna. No debemos olvidar que el derecho de las confesiones religiosas y empresas de tendencia a discriminar a sus trabajadores por razón de religión o convicciones, encuentra su fundamento en su autonomía para elegir los medios que mejor garanticen la satisfacción de sus propios fines, que deriva del juego conjunto de los artículos 10 y 12 de la Carta Europea de Derechos Fundamentales de la Unión Europea, donde se reconocen, respectivamente, la libertad religiosa e ideológica y el derecho de asociación.

El Tribunal de Justicia de la Unión Europea en la Sentencia IR v. $\mathrm{JQ}^{41}$ (2018) ha aportado algunos criterios para su determinación, al resolver una cuestión prejudicial en relación con el derecho de las empresas de tendencia -en este caso, un hospital católico- a someter a sus trabajadores a obligaciones de lealtad frente a su ideario. El Tribunal se-

40 Sobre el concepto de empresa de tendencia deducible de la jurisprudencia del Tribunal Europeo de Derechos Humanos y del Tribunal de Justicia de la Unión Europea, vid. J.-P. SCHOUPPE, Hacia un régimen jurídico de las empresas de tendencia a la luz de la jurisprudencia europea, Ius Canonicum 59 (2019) 121 y ss.

41 Sentencia IR v. JQ, de 11 de septiembre de 2018, asunto C-68/17. Un comentario a esta sentencia puede verse en G. MORENO BOTELLA, La superflua excepción a la prohibición de discriminación y el deber de lealtad en organizaciones de tendencia en la Directiva 2000/78, Diario La Ley 9339 (2019). 
ñaló que dado los términos abstractos en que está redactado el artículo 4.2 de la Directiva, no se puede reservar su aplicación a entidades que hayan adquirido determinada personalidad jurídica. Por tanto, un hospital católico perteneciente a una sociedad limitada que tiene por objeto social el desempeño de funciones de Cáritas puede considerarse como empresa de tendencia a efectos del art. 4.2 de la Directiva. De esta manera, la expresión "empresas de tendencia" incluye las entidades que se han constituido con arreglo al Derecho privado en la medida en que tengan una ética basada en la religión o las convicciones.

En este punto, resulta muy esclarecedor referirse a las Conclusiones del Abogado General Wathelet, dirigidas al Tribunal en este mismo asunto $^{42}$, donde defiende la consideración del hospital católico como empresa de tendencia no por el mero hecho de estar sujeto al control del arzobispo católico de Colonia y de que su objeto social consista en el desempeño de las funciones de Cáritas, sino en tanto su práctica se ajusta a la doctrina de la Iglesia Católica, de modo que resulta distinguible de la de otros hospitales. A este respecto -indica Wathelet- presenta particular relevancia la adecuación de la práctica del hospital a la doctrina católica en materia de aborto, eutanasia, contracepción y las demás medidas de control de la reproducción. De esta forma, si se demuestra que actúan de conformidad con el Catecismo de la Iglesia Católica, cabría considerar a dicha entidad como empresa de tendencia ${ }^{43}$.

Vid. Opinión General Abogado Melchior Wathelet, de 31 de mayo de 2018, Asunto C-68/17, IR v. JQ, aps. 46-48.

43 Como punto de contraste cabe señalar que nuestro Tribunal Constitucional en su Sentencia 106/1996, de 12 de junio -antes, por tanto, de la entrada en vigor de la Directiva-, consideró que un hospital perteneciente a la Orden de San Juan de Dios no podía considerarse como una empresa de tendencia ya que su finalidad públicamente reconocida no era la de difusión de un ideario religioso sino la asistencial o sanitaria. Por ello, aunque el centro hospitalario cumpla su función social con una finalidad caritativa, y de este modo exista una conexión con el ideario religioso de la entidad titular, su existencia no puede tener el mismo efecto que tiene el ideario de un colegio sobre los profesores. Lo relevante -afirmaba la sentencia- no es la motivación subjetiva de la entidad titular -que ciertamente ha podido crear tal empresa al servicio de su ideario- sino el público reconocimiento de la función social que cumple el centro donde se presta el trabajo, que en este caso es la hospitalaria. Lo que implica, en definitiva, que no puede extenderse de forma incondicionada al hospital el ideario propio de la entidad titular, aun admitiendo tanto el carácter religioso de la entidad titular del hospital como que dicho centro se halla al servicio de una finalidad caritativa. 
Por otra parte, como la Directiva se refiere también a organizaciones públicas, se ha discutido si pueden ser considerados como organizaciones de tendencia aquellos estados que han adoptado un modelo de estricta neutralidad en materia religiosa -que operaría, se dice, como un ideario- de forma que pudieran someter a sus trabajadores a limitaciones en el ejercicio de su derecho de libertad religiosa ${ }^{44}$. Nos encontramos ante una cuestión sobre la que el Tribunal de Justicia no ha llegado todavía a pronunciarse. No obstante, a mi juicio tal consideración entrañaría una interpretación demasiado amplia del concepto de «empresa de tendencia» que no tendría cabida en esta previsión, en tanto, por una parte, faltaría la conexión con el derecho a la libertad religiosa e ideológica que justifica esta excepción y, de otro, aminoraría innecesariamente la protección de los trabajadores del sector público, al margen de lo desacertado de justificar excepciones a la igualdad de los ciudadanos con base en principios organizativos del Estado que pretenden, precisamente, garantizar la igualdad religiosa de todos sin respaldos ni obstáculos indebidos ${ }^{45}$.

\section{b) Alcance del derecho a discriminar por razón de religión}

A la hora de precisar el alcance del derecho de confesiones y empresas de tendencia a discriminar a sus trabajadores por razón de religión, hay que prestar atención a la Sentencia Vera Egenberger ${ }^{46}$, del

44 Vid. E. HOWARD, Study on the implementation of Directive 2000/78/EC with regard to the principle of non-discrimination on the basis of religion or belief, cit., 49-50; E. DALY, Laïcité in the Private Sphere? French Religious Liberty After the Baby-Loup Affair, Oxford Journal of Law and Religion May (2016) 212 y ss. Por su parte, el Tribunal Europeo de Derechos Humanos en su discutible Sentencia Ebrahimian, parece aceptar que la neutralidad religiosa estatal constituye un objetivo legítimo para justificar la prohibición de utilizar el velo islámico por parte de una trabajadora social de un hospital público francés. Vid. Ebrabimian v. Francia, de 26 de noviembre de 2015.

45 Tal planteamiento fue rechazado de plano por la Abogada General Kokott, en sus Conclusiones en el caso Achbita (2016), donde puso de manifiesto que la identidad nacional caracterizada por la laicidad no puede limitar el ámbito de aplicación de la Directiva, sino que puede modular la aplicación del principio de igualdad de trato.

46 Sentencia del Tribunal de Justicia de la Unión Europea, de 17 de abril de 2018, en el caso C-414/16, Vera Egenberger v. Evangelisches Werk für Diakonie und Entwicklung e.V. Un comentario a esta sentencia puede verse en M. MORENO ANTÓN, «El artículo 4.2 de la Directiva 2000/78 y su valoración por el T7UE: la Sentencia de 17 de abril de 2018, asunto C-414/16, Vera Egenberger», Revista General de Derecho Canónico y Eclesiástico del Estado 47 (2018). 
Tribunal de Justicia de la Unión Europea (2017), donde se resuelve una cuestión perjudicial planteada por un Tribunal alemán -Bundesarbeitsgericht- en el marco de un proceso laboral en que una solicitante de empleo afirmaba que había sido discriminada por una entidad vinculada a la Iglesia evangélica alemana al no haber sido contratada, por no pertenecer a una Iglesia protestante, para el desempeño de actividades de carácter secular: la elaboración de informes paralelos sobre la Convención de las Naciones Unidas relativa a la eliminación de todas las formas de discriminación racial.

El Tribunal puso de manifiesto el carácter limitado de este derecho subrayando que estas entidades no pueden decidir autónomamente - esto es, al margen de cualquier escrutinio estatal- si la religión del trabajador constituye un requisito profesional esencial, legítimo y justificado respecto del "ethos" de la organización, a la luz de las actividades a realizar o por el contexto en que se llevan a cabo.

Esta afirmación se basa en una doble consideración. Por una parte, en que la propia redacción del artículo 4.2 establece (implícitamente) un control externo acerca de si la característica religiosa del trabajador constituye un requisito profesional esencial, legítimo y justificado. Y, por otra, en que el objeto de este precepto está en luchar contra la discriminación por motivos religiosos, de suerte que pretende garantizar un justo equilibrio entre el derecho a la autonomía de las Iglesias y organizaciones de tendencia y el derecho de los trabajadores a no sufrir discriminación por razón de religión.

Cabe recordar, en este momento, la doctrina del Tribunal Europeo de Derechos Humanos en relación con la autonomía de las confesiones religiosas $^{47}$, donde tras reconocer el derecho de estas entidades a reaccionar frente a cualquier injerencia que pueda afectar a su autonomía religiosa, se advierte que no basta una mera alegación por parte de una comunidad de que existe una amenaza real o potencial a su doctrina, para justificar una injerencia sobre el derecho de sus miembros al ejercicio de sus derechos fundamentales sino que se debe probar, a la luz de las circunstancias de cada caso, que el riesgo alegado sea probable y

47 Vid. I. LEIGH, Balancing Religious Autonomy and Other Human Rights Under the European Convention, Oxford Journal of Law and Religion 1 (2012) 109-126; M. KIVIORG, Religious Autonomy in the ECHR, Derecho y Religión (2013) 131-141. 
esencial y, además, que la medida adoptada resulte proporcionada para eliminar ese riesgo y no sirva a otros propósitos espurios ajenos al ejercicio de la libertad religiosa colectiva ${ }^{48}$.

La Sentencia Vera Egenberger, al precisar cuáles son los términos en que ese control judicial puede ser llevado a cabo, advierte de que los tribunales nacionales no pueden entrar a valorar la legitimidad de la doctrina religiosa o ideológica de la entidad empleadora, debiendo limitarse a garantizar que la decisión de discriminar a los trabajadores por razón de religión o convicciones, resulta legítima en cuanto cumple con los criterios de la Directiva, esto es, que la característica religiosa del trabajador constituye un requisito profesional esencial, legítimo y justificado respecto de la ética de dicha organización.

El Tribunal señaló que la legalidad de una discriminación religiosa se supedita a la existencia objetiva de un vínculo directo entre el requisito profesional (religión o convicciones) y la actividad de que se trate, que «puede derivarse o bien de la naturaleza de esta actividad, por ejemplo, cuando implica participar en la determinación de la ética de la Iglesia o la organización en cuestión o colaborar en su tarea de predicación, o bien del contexto en que debe desarrollarse dicha actividad, como la necesidad de garantizar una representación fidedigna de la Iglesia o de la organización a efectos externos» ${ }^{49}$.

Esta Sentencia es importante también porque viene a precisar qué debe entenderse por requisito profesional "esencial, legítimo y justificado". A este respecto indica que la exigencia de que la característica religiosa sea "esencial" significa que debe resultar necesaria debido a la importancia de la actividad profesional «para la afirmación de esa doctrina o del ejercicio de su derecho a la autonomía». El carácter "legítimo" quiere garantizar que la pertenencia a la religión no sirva para promover un objetivo ajeno a dicha doctrina o al ejercicio de su autonomía. Por último, el carácter "justificado" alude a que la Iglesia u organización está obligada a demostrar que el riesgo alegado de vulneración de su doctrina es probable y grave, de tal modo que el establecimiento de dicho requisito resulte verdaderamente necesario.

48 Sentencia Sindicatul Pastorul Cel Bun v. Rumanía (Gran Sala), de 9 de julio de 2013, ap. 159.

49 Vid. ap. 63. 
Por lo demás, aunque el 4.2 de la Directiva -a diferencia del 4.1no establezca que el requisito profesional sea "proporcionado", no debe ignorarse que cualquier diferencia de trato debe hacerse respetando los principios generales del Derecho comunitario. Dado que entre ellos se encuentra el principio de proporcionalidad, los tribunales domésticos deben comprobar que el requisito «religioso» es apropiado y no excede lo necesario para alcanzar el objetivo previsto.

\subsubsection{Derecho español}

En lo que se refiere a la aplicación de esta excepción en Derecho español, debemos advertir que el contenido del artículo 4.2 no fue transpuesto a nuestro ordenamiento jurídico. Contrasta esta situación con la de otros estados europeos donde la normativa laboral sí contempla expresamente esta posibilidad, como es el caso del Reino Unido, Italia o Alemania, entre otros ${ }^{50}$.

En todo caso, nuestros Tribunales han reconocido en alguna ocasión la legitimidad del despido de un trabajador de empresas de tendencia por razones ideológicas. Cabe aludir, en este sentido, a la Sentencia del Tribunal Superior de Justicia de Madrid de 8 de julio de 2014 que consideró que el despido de un trabajador de un partido político por sus declaraciones en contra de la posición del partido no podía calificarse como discriminatorio. En efecto, allí se afirma que una de las conse-

50 Decreto legislativo italiano 216 de 9 de julio de 2003, de aplicación de la Directiva 2000/78/CE para la igualdad de trato en materia de ocupación y de condiciones de trabajo, donde se indica: Non costituiscono atti di discriminazione ai sensi dell'articolo 2 le differenze di trattamento basate sulla professione di una determinata religione o di determinate convinzioni personali che siano praticate nell'ambito di enti religiosi o altre organizzazioni pubbliche o private, qualora tale religione o tali convinzioni personali, per la natura delle attivita' professionali svolte da detti enti o organizzazioni o per il contesto in cui esse sono espletate, costituiscano requisito essenziale, legittimo e giustificato ai fini dello svolgimento delle medesime attivita'. De la misma manera, en el Reino Unido, la Equality Act (2010) dispone «A person (A) with an ethos based on religion or belief does not contravene a provision mentioned in paragraph 1(2) by applying in relation to work a requirement to be of a particular religion or belief if A shows that, having regard to that ethos and to the nature or context of the work -(a) it is an occupational requirement, (b) the application of the requirement is a proportionate means of achieving a legitimate aim, and (c) the person to whom A applies the requirement does not meet it (or A has reasonable grounds for not being satisfied that the person meets it)». 
cuencias más evidentes que puede tener la dependencia jurídica y la sujeción a un criterio ideológico es la posibilidad de ejercer un despido disciplinario por disonancia con la ideología empresarial. El despido así es el cauce que permite preservar la ideología empresarial frente al ataque del trabajador.

La misma doctrina resulta de aplicación a las confesiones religiosas cuando deciden el despido de alguno de sus trabajadores por no compartir la doctrina religiosa. Aunque, estrictamente no se trata de trabajadores de las confesiones religiosas, nuestros tribunales han reconocido el derecho de las confesiones religiosas a prescindir de aquellos profesores de religión en centros públicos que no respetan en su vida privada la doctrina religiosa que transmiten ${ }^{51}$.

\subsection{El sometimiento de los trabajadores de confesiones religiosas} y empresas de tendencia a obligaciones acrecentadas de lealtad

\subsubsection{Las previsiones de la Directiva}

Uno de los métodos más útiles que tienen las confesiones religiosas y empresas de tendencia para garantizar el cumplimiento de sus propios fines es someter a sus trabajadores a obligaciones de lealtad frente a su doctrina o ideario ${ }^{52}$.

51 Por todas, vid. Sentencia del Tribunal Constitucional 38/2007, de 15 de febrero; Sentencia 128/2007, de 4 de junio, confirmada por la Gran Sala del Tribunal Europeo de Derechos Humanos en la Sentencia Fernández Martínez v. España, de 12 de junio de 2014. Sobre estas cuestiones puede verse, J. OTADUY, La idoneidad de los profesores de religión católica y su desarrollo jurisprudencial en España, Estudios eclesiásticos: Revista de investigación e información teológica y canónica 88 (2013) 849-871; S. CAÑAMARES ARRIBAS, El control jurisdiccional de la autonomía de la Iglesia católica en la designación de los profesores de religión, Revista Española de Derecho Canónico 66 (2009) 275-292; J. MARTÍNEZ-TORRón, La autonomía religiosa y la vida privada de los profesores de religión en la jurisprudencia de Estrasburgo: el caso Fernández Martínez, en $\mathrm{M}^{\mathrm{a}} \mathrm{MO}-$ RENO ANTÓN (coord.), Sociedad, derecho y factor religioso: estudios en honor del profesor Isidoro Martín Sánchez, Comares, 2017, 374-390; M. J. VALERO, Autonomía institucional de las confesiones religiosas y derecho al respeto de la vida privada y familiar en Estrasburgo: la sentencia de la Gran Sala del TEDH Fernández Martínez c España, Revista General de Derecho Canónico y Derecho Eclesiástico del Estado 36 (2014).

52 Sobre el contenido de esta prerrogativa me remito a mi trabajo S. CAÑAMARES ARRIBAS, Obligaciones de lealtad y discriminación religiosa de los trabajadores de las confesiones religiosas y empresas de tendencia, Revista La Ley Unión Europea 64 (2018). 
El Tribunal de Justicia de la Unión Europea tuvo ocasión de referirse al alcance de este derecho en su Sentencia IR v. JQ -anteriormente aludida- donde se viene a resolver una cuestión prejudicial planteada por un Tribunal alemán -Bundesarbeitsgericht- en el marco de un proceso laboral en que un médico católico -jefe del servicio de medicina interna- de un hospital también católico alegaba haber sido discriminado por motivos religiosos frente a otros trabajadores no católicos, ya que había sido despedido por no respetar la doctrina de la Iglesia en relación con la sacramentalidad del matrimonio, al haber celebrado un segundo matrimonio civil después del divorcio de su primera unión canónica.

El Tribunal de Justicia subraya que el derecho de estas entidades a someter a sus trabajadores a obligaciones de lealtad no es sino una concreción del derecho de estas entidades a discriminar a sus trabajadores por motivos religiosos o ideológicos. La particularidad se encuentra en que, en este caso, el requisito profesional consistiría en la observancia de una actitud de buena fe y de lealtad hacia la ética de dicha Iglesia u organización. Eso supone, por tanto, que, para que dichas obligaciones sean admisibles, su contenido debe resultar esencial, legítimo y justificado respecto de la doctrina o ideario de la organización en atención a la naturaleza de la actividad o al contexto en que se preste.

Al tratarse de una concreción del derecho de estas entidades a discriminar a sus empleados por motivos religiosos o ideológicos, la sentencia recuerda, siguiendo la doctrina sentada en Vera Egenberger, que tales sometimientos están sujetos a control por parte de los tribunales para evitar situaciones de discriminación derivadas de la vinculación de los trabajadores a obligaciones de lealtad desproporcionadas, esto es, que no estén justificadas por la protección de la autonomía (libertad religiosa colectiva) de las confesiones religiosas.

Por último, es importante indicar que el Tribunal de Justicia considera legítimo en IR v. JQ que estas entidades puedan discriminar a sus trabajadores entre sí a la hora de someterles a diferentes obligaciones de lealtad en función de la religión que profesen. Para ello seguirá siendo necesario que la religión o las convicciones constituyan un requisito profesional esencial, legítimo y justificado respecto de dicha doctrina o ideario poniéndose el foco, más aún si cabe, en la diferente naturaleza 
de las actividades profesionales que lleven a cabo unos y otros trabajadores o al diferente contexto en el que se desarrollan ${ }^{53}$.

\subsubsection{Derecho español}

Aunque -conviene reiterarlo- el contenido del artículo 4.2 de la Directiva no fue transpuesto a nuestro Derecho, nuestros tribunales se han pronunciado en algunas ocasiones acerca del alcance de este derecho. Cabe traer a colación la Sentencia del Tribunal Superior de Justicia de Valencia de 30 de julio de 2015 donde se declaraba discriminatorio el despido de un profesor de bachillerato que, aun compartiendo el ideario educativo del colegio, fue sustituido por otro profesor más afín y activo en su difusión.

El demandante alegó que el despido resultaba discriminatorio por razón de religión, aportando como indicios el hecho de haber sido sustituido por otro profesor con menos experiencia y formación académica, pero «con una importante formación católica cristiana, que había estudiado en centros con vinculación a dicho ideario, formación que cultiva y promueve a través de las redes sociales».

Por su parte, la empresa no consiguió acreditar que el despido fuera ajeno a todo propósito discriminatorio dado que el profesor no se mostró contrario al ideario del centro docente. Parece que fue su falta de desarrollo o de tendencia hacia el ideario lo que llevó al colegio al cese del profesor para sustituirlo posteriormente por otro empleado afín y activo en la aplicación y difusión del ideario del centro.

A la luz de estas circunstancias, el Tribunal califica el despido de discriminatorio, en tanto las obligaciones de lealtad frente al ideario educativo resultaban desproporcionadas, ya que no se limitaban a respetarlo, sino que comprendían una adhesión en todos tus términos que llevara al docente a ser activo en su difusión tanto dentro como fuera del entorno laboral.

53 Como término de comparación, un estudio sobre la posición del Tribunal Europeo de Derechos Humanos sobre esta cuestión puede verse en L. RUANo EsPINA, «Despido del trabajador, por confesión religiosa o institución dependiente de ella, debido a actos o conductas doctrinalmente divergentes», en A. MOTILla (coord.), La jurisprudencia del Tribunal Europeo de Derechos Humanos en torno al derecho de libertad religiosa en el ámbito laboral, Comares, 2016, 156-178. 
En este punto, conviene recordar la posición mantenida por el Tribunal Constitucional en su Sentencia 5/1981, de 13 de febrero, donde se afirma que la existencia de un ideario no obliga al profesor a convertirse en apologista del mismo, ni a transformar su enseñanza en propaganda o adoctrinamiento, ni a subordinar a ese ideario las exigencias que el rigor científico impone a su labor. El profesor es libre en el ejercicio de su actividad específica; sin embargo, su ejercicio ha de ser compatible con la libertad del centro, del que forma parte el ideario, de modo que no puede amparar ataques abiertos o solapados contra ese ideario.

El Tribunal Constitucional ha distinguido las obligaciones de lealtad de estos docentes de las que recaen sobre los profesores de religión, ya que según dispuso en su Sentencia 38/2007, de 20 de febrero, la vinculación con el ideario religioso es mucho mayor en el caso de estos últimos, a quienes se les exige la adhesión a la doctrina católica como elemento determinante de la propia capacidad para impartir la asignatura de religión católica.

Por lo tanto, cuando se trata del sometimiento de trabajadores a obligaciones de lealtad, el criterio decisivo para calificar como discriminatoria determinada decisión o criterio empresarial está en valorar la proporcionalidad de la obligación de lealtad impuesta a los trabajadores atendiendo a la naturaleza de las actividades que realizan y a su impacto frente a los fines religiosos o ideológicos que pretende cumplir la entidad empleadora.

\section{Conclusiones}

Aunque son indudables los avances en materia de protección de la libertad religiosa en las relaciones laborales que se han producido en nuestro Derecho, todavía son detectables algunas carencias que se ponen especialmente de relieve cuando se aplica una perspectiva comparada. Algunas de ellas, viene referidas a la protección del trabajador frente a ciertas situaciones de discriminación y otras afectan directamente al ejercicio colectivo de la libertad religiosa por parte de confesiones y empresas de tendencia.

En lo que se refiere a la protección de la libertad religiosa del trabajador, resulta destacable la falta de reconocimiento en el derecho europeo del llamado derecho de acomodo en materia religiosa que, por 
lo demás, se encuentra consolidado en otros ordenamientos jurídicos como el norteamericano o el canadiense.

Es cierto que, aunque la Directiva 2000/78, en su artículo 5, limita el derecho al acomodo a la discapacidad de los trabajadores, no excluye la posibilidad de que los estados miembros dispensen una protección mayor en materia de igualdad y no discriminación extendiendo el reconocimiento de este derecho al ámbito de la religión.

Sin embargo, desde mi punto de vista, existe en el ámbito europeo una clara tendencia a evitar la extensión del derecho al acomodo en materia religiosa que fácilmente puede contagiarse a los derechos nacionales. Al respecto puede traerse a colación el Informe de la Red Europea de Expertos Juristas en materia de no discriminación (2013) -auspiciado por la Comisión Europea- donde se pusieron de manifiesto algunos argumentos en contra de la extensión del "duty to accommodate" a las creencias religiosas del trabajador. En efecto, el Informe objetaba, por ejemplo, que este tipo de acomodación supondría priorizar los valores religiosos frente a los seculares, discutiendo por qué la religión puede fundamentar una acomodación de los horarios laborales -descansando, por ejemplo, en determinado día de la semana- frente a quienes reclaman el mismo tratamiento con base en otras razones de tipo secular: disfrutar de la familia, participar en actividades de determinadas asociaciones, etc.

Creo que bajo esta diferencia de criterio late la idea de que aquellas características inherentes a la persona -sexo, edad, discapacidadque conforman su identidad merecen un grado de protección mayor frente a aquellas otras que, como la religión, tiene un carácter electivo. Sin embargo, no se debe olvidar que la religión tiene un componente identitario importante, y que rebajar su nivel de protección supone comprometer el libre ejercicio de la religión en el ámbito laboral.

En lo que se refiere la protección de la libertad religiosa colectiva, las carencias detectadas resultan imputables al Derecho español pues, como hemos puesto de manifiesto en este trabajo, no se ha producido una transposición completa del contenido de la Directiva a nuestro Derecho, ya que -al contrario de lo que ha ocurrido en otros ordenamientos nacionales- no se recoge el derecho de las entidades religiosas y empresas de tendencia a discriminar por razón de religión a los trabajadores de una manera más amplia que el resto de empleadores. 
Según algunas opiniones, esta omisión podría deberse a que esta posibilidad ya estaba recogida en nuestro Derecho desde el momento en que la propia Ley Orgánica 5/1980, de Libertad Religiosa, permite a las confesiones establecer cláusulas de salvaguarda de la propia identidad que también pueden proyectarse en los contratos laborales. No obstante, desde mi punto de vista, esta conclusión no resulta tan clara porque dicha posibilidad podría entenderse satisfecha en los términos del artículo 4.1 de la Directiva, que es el que ha sido traspuesto en nuestro ordenamiento, esto es, exigiendo que la religión sea un requisito profesional y determinante del puesto de trabajo, lo que limitaría considerablemente las posibilidades de estas entidades de seleccionar a sus trabajadores cuando no vayan a desempeñar actividades de naturaleza religiosa.

Por tanto, teniendo en cuenta la falta de efecto directo horizontal de las Directivas, la mejor protección de los derechos fundamentales en juego -de un lado, la igualdad religiosa e ideológica del trabajador y, de otro, la autonomía de las confesiones religiosas- recomendaría transponer el artículo 4.2 de la Directiva en nuestro Derecho en sus propios términos, tal y como, por lo demás -insisto- ha ocurrido en otros estados de la Unión Europea. 


\section{Bibliografía}

CaÑamares Arribas, S., Festividades religiosas e igualdad laboral, Revista La Ley Unión Europea Mayo (2019).

—, Igualdad religiosa en las relaciones laborales, Aranzadi, 2018.

—, Obligaciones de lealtad y discriminación religiosa de los trabajadores de las confesiones religiosas y empresas de tendencia, Revista La Ley Unión Europea 64 (2018).

-, El control jurisdiccional de la autonomía de la Iglesia católica en la designación de los profesores de religión, Revista Española de Derecho Canónico 66 (2009).

ChabID, S. O., Religious Accommodation in the Workplace: Improving the Legal Reasoning of the European Court of Human Rights, en AA. Vv., A test of faith? Religious diversity and accommodation in the European workplace, Ashgate Ltd., 2012.

Coglievina, S., Diritto antidiscriminatorio e religione nel diritto dell'Unione Europea, Derecho y Religión 11 (2016).

Daly, E., Laïcite in the Private Sphere? French Religious Liberty After the Baby-Loup Affair, Oxford Journal of Law and Religion May (2016).

GILEs, J., Neutrality in the Business Sphere - An Encroachment on Rights Protection and State Sovereignty?, Oxford Journal of Law and Religion 7, Issue 2, June (2018).

HowarD, H., Study on the implementation of Directive 2000/78/EC with regard to the principle of non-discrimination on the basis of religion or belief, cit., EPRS, 2016.

KIVIORG, M., Religious Autonomy in the ECHR, Derecho y Religión (2013).

LeIGH, I., Balancing Religious Autonomy and Other Human Rights Under the European Convention, Oxford Journal of Law and Religion 1 (2012).

López-Sidro López, A. - PAlomino Lozano, R., ¿Cabe la discriminación positiva en relación con el factor religioso?, Revista General de Derecho Canónico y de Derecho Eclesiástico del Estado 25 (2011).

MARTÍNEZ-TORRón, J., La autonomía religiosa y la vida privada de los profesores de religión en la jurisprudencia de Estrasburgo: el caso Fernández Mar- 
tínez, en $\mathrm{M}^{\mathrm{a}}$ MORENO ANTÓN (coord.), Sociedad, derecho y factor religioso: estudios en honor del profesor Isidoro Martín Sánchez, Comares, 2017.

Moreno Antón, M., El artículo 4.2 de la Directiva 2000/78 y su valoración por el T7UE: la Sentencia de 17 de abril de 2018, asunto C-414/16, Vera Egenberger, Revista General de Derecho Canónico y Eclesiástico del Estado 47 (2018).

Moreno Botella, G., La superflua excepción a la probibición de discriminación y el deber de lealtad en organizaciones de tendencia en la Directiva 2000/78, Diario La Ley 9339 (2019).

Navarro-Valls, R. - Martínez-Torrón, J., Conflictos entre conciencia y ley. Las objeciones de conciencia, Iustel, Madrid 2012.

OTADUY, J., La idoneidad de los profesores de religión católica y su desarrollo jurisprudencial en España, Estudios eclesiásticos: Revista de investigación e información teológica y canónica 88 (2013).

Palomino, R., Igualdad y no discriminación religiosa en el Derecho de la Unión Europea. A propósito de las conclusiones en los casos Achbita y Bougnaoui, Revista latinoamericana de Derecho y Religión 2 (2016).

PIN, A., Is there a place for Islam in the West? Adjudicating the Muslim beadscarf in Europe and the United States, Notre Dame Law Review 35 (2017).

RElaÑo, E., Towards Substantive Equality for Religious Believers in the Workplace? Two Supranational European Courts, Two Different Approaches, Oxford Journal of Law and Religion 5 (2016).

Ruano Espina, L., Despido del trabajador, por confesión religiosa o institución dependiente de ella, debido a actos o conductas doctrinalmente divergentes, en A. MoTILLA (coord.), La jurisprudencia del Tribunal Europeo de Derechos Humanos en torno al derecho de libertad religiosa en el ámbito laboral, Comares, 2016.

SCHOUPPE, J.-P., Hacia un régimen jurídico de las empresas de tendencia a la luz de la jurisprudencia europea, Ius Canonicum 59 (2019).

VAlero, M. J., Autonomía institucional de las confesiones religiosas y derecho al respeto de la vida privada y familiar en Estrasburgo: la sentencia de la Gran Sala del TEDH Fernández Martínez c España, Revista General de Derecho Canónico y Derecho Eclesiástico del Estado 36 (2014). 
OTROS ESTUDIOS 
